\title{
Pediatric spinal deformity correction in children with cerebral palsy: natural history and correction techniques
}

\author{
S.O. Ryabykh ${ }^{1}$, A.V. Gubin ${ }^{2}$, D.M. Savin ${ }^{1}$, E.Yu. Filatov ${ }^{1}$, P.V. Ochirova' ${ }^{1}$ T.V. Ryabykh ${ }^{1}$, O.M. Sergeenko ${ }^{1}$
}

${ }^{1}$ Ilizarov National Medical Research Centre for Traumatology and Orthopedics, Kurgan, Russian Federation

${ }^{2}$ National Medical Research Center of Traumatology and Orthopedics n.a. N.N. Priorov, Moscow, Russian Federation

\begin{abstract}
Introduction Spinal deformity is one of major orthopaedic manifestations of cerebral palsy (CP). Despite the prevalence of the nosologic condition there is a deficiency in the availability of criteria for screening and management of the spinal pathology in $\mathrm{CP}$ patients, difficulties in interdisciplinary logistics, lack of registry and restraints in the continuity of the rehabilitation system. The purpose of the work was to focus the attention of mainstream audience of dedicated experts on the aspects of the course and correction techniques of spinal deformities in CP patients. Evidence level 5 (UK Oxford, version 2011). Results The type of spinal deformity depends on the functional level classified with the GMFCS. Vertebral evaluation included identification of the leading component of the deformity, apex location, mobility, trunk balance, chest deformity, type of pelvic obliquity, the way contractures and dislocation of the femoral heads affected the lumbar spine mobility. The goal of spinal deformity correction in CP patients is to maintain or improve the functionality of the patients, improve the quality of life for the patient and the family. The use of transpedicular multi-support fixation systems and bone allografts can be recommended for bone fusion in the patients. Spinal fixation can be extended from the upper thoracic vertebrae down to the pelvis. Dynamic fixation systems, multilevel or multi-rod fixation can be an option depending on the age, extent of the maturity of the axial skeleton and size of the curve. Conclusion The severity of manifestations of spinal deformity increases in CP patients with greater level of global motor functions and does not depend on the skeletal maturity. Conservative treatment is ineffective at a long term. Correction and instrumentation transpedicular fixation allows for three-dimensional correction without the need for anterior fusion. Surgical treatment significantly improves body balance, functional level and quality of life.

Keywords: cerebral palsy, cerebral palsy in children, spinal pathology, spinal deformity, scoliosis, bracing, posterior spinal fusion, pelvis fixation, complications
\end{abstract}

\section{BACKGROUND}

Spinal deformity is one of the leading manifestations of orthopaedic complications of cerebral palsy (CP). Although the more common term "cerebral palsy" was used as the common term in the post-Soviet countries, we consider "cerebral palsy" to be a more adequate term based on age continuity. It is paradoxical that there is a lack of information in the assessment of spinal pathology with the widespread nosologic condition. So, the search queries for the key phrases "cerebral palsy" yielded about 23 thousand publications in the PubMed while a little more than 2 thousand reported were found for the query "cerebral palsy deformity", and only 101 publications were detected for "cerebral palsy spine deformity", which is less than $0.4 \%$ of the total number of works. Aspects of spinal pathology have been described in two prominent monographs $[1,2]$. Eight protocols are presented in the Cochrane Library, and none of them involves surgical correction of orthopaedic complications: out of 74 reviews, the control of spinal deformity was indirectly reported in one publication [3]. At the same time, four clinical trials on spinal deformities and outcomes of the treatment have been reported [4-7].

Inadequate logistics (geographical, professional, age related); lack of registries, as well as evidencebased rehabilitation centers; underestimation of the "motor ceiling" of rehabilitation; barriers to the continuity of the rehabilitation system mitigate against timely screening, management of spinal pathology in $\mathrm{CP}$ patients and pathogenetic treatment. The above factors lead to the high rate of disability, limited self care, loss of social functioning skills, low quality of life and life expectancy of the patients $[8,9,10]$. The purpose of the work was to focus the attention of mainstream audience of dedicated experts on the aspects of the course and correction techniques for spinal deformities in CP patients. Evidence level 5 (UK Oxford, version 2011).

\section{RESULTS}

The characterisation of the spinal curve depends on the functional level as classified with GMFCS (Gross Motor Function Classification System) system. Lonstein and Akbarnia [11] identified 2 most common types of scoliosis in cerebral palsy: group 1 including single thoracic, double thoracic or lumbar arch without pelvic obliquity, usually observed in ambulatory patients, and group 2 comprising extended thoracolumbar or $\mathrm{C}$-shaped arches with pelvic obliquity, often observed in patients with low activity 
level (GMFCS groups IV and V). Hyperlordosis of the lumbar spine or kyphoscoliosis of the thoracic spine are also common in CP. Review of the rate of the curve progression in the natural course has shown that a mobile arc normally develops at the age of 3 to 10 years and rapidly transforms into a rigid condition.

The vertebral status is determined by the leading component of deformity (scoliosis, lordosis, kyphosis), location of the apex, mobility (Fig. 1a), trunk balance (Fig. 1b), chest deformity (Fig. 1c), the type of pelvic obliquity, contractures and dislocation of the femoral heads affecting the mobility of the lumbar spine. Disturbed balance of the spine as a deviation of the C7 vertebra from the CSVL (Central Sacrum Vertical Line) and PSVL (Posterior Sacrum Vertical Line) of more than $4 \mathrm{~cm}$ is indicative of inability to maintain balance due to spasticity and retraction (often asymmetric) of the axial musculature and leads to sternal torsion, disturbed skeletopy of internal organs and frequent dysfunction of the lungs and the heart. Scoliosis can also be the peak of the "TerribleTriad" [2] resulting from pelvic obliquity associated with unilateral or asymmetric hip dislocation and it is important with the leading component of the pelvic obliquity to be identified as either suprapelvic in a rigid deformity of the spine or infrapelvic in flexionadduction contracture of the hip [1] (Fig. 2).

Monitoring and correction of spinal deformity

The treatment of spinal deformity in CP is aimed at maintaining or improving the functional capabilities of patients, as well as the quality of life. Decisionmaking about treatment should be individual and based on a thorough assessment of the risk-benefit ratio depending on the severity of concomitant diseases [12].

Conservative treatment of spinal deformity in $\mathrm{CP}$ includes a combined use of orthopaedic devices, technical means of rehabilitation for adaptation to an upright position and sitting, physiotherapy and medications to address spasticity and prevent contractures. Bracing that is normlly employed for the treatment of spinal deformity, appears to be ineffective in most cases [1315]. In addition to that, extrapyramidal symptoms and seizures, as well as the restricted chest movements associated with wearing a corset, can aggravate the lung deficiency and lead to pressure ulcers. Treatment of spinal deformity and non-surgical treatment of spasticity with botulinum toxin was evaluated in a limited number of cases with short follow-up periods, but with encouraging results. Nuzzo et al. [16] reported that botulinum toxin injected on the concave side of the deformity in patients who required a delayed surgical intervention increased the effectiveness of bracing and stopped the progression of the curvature. However, the temporary effectiveness of botulinum toxin prevents its use at later stages due to the rigidity of spinal deformity and gross imbalance.

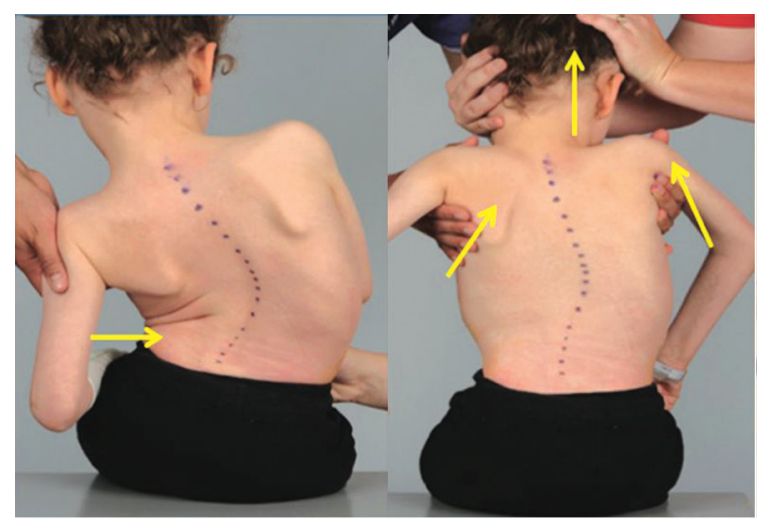

a

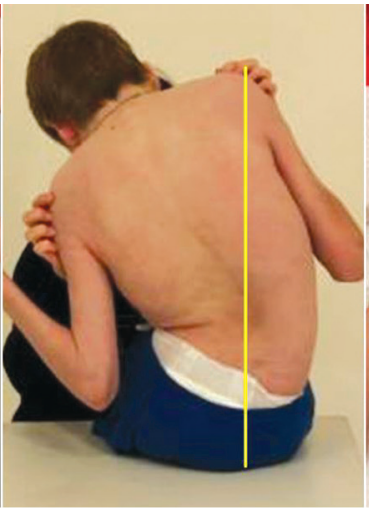

b

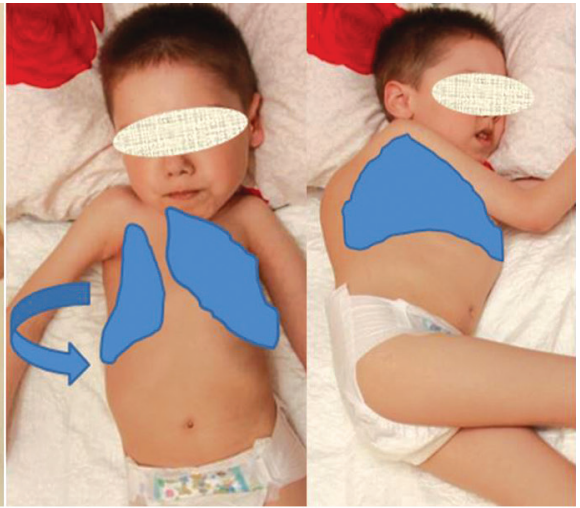

C

Fig. 1 Clinical landmarks for identifying spinal mobility (a);disturbed frontal trunk balance (b); torsion chest deformity (c)

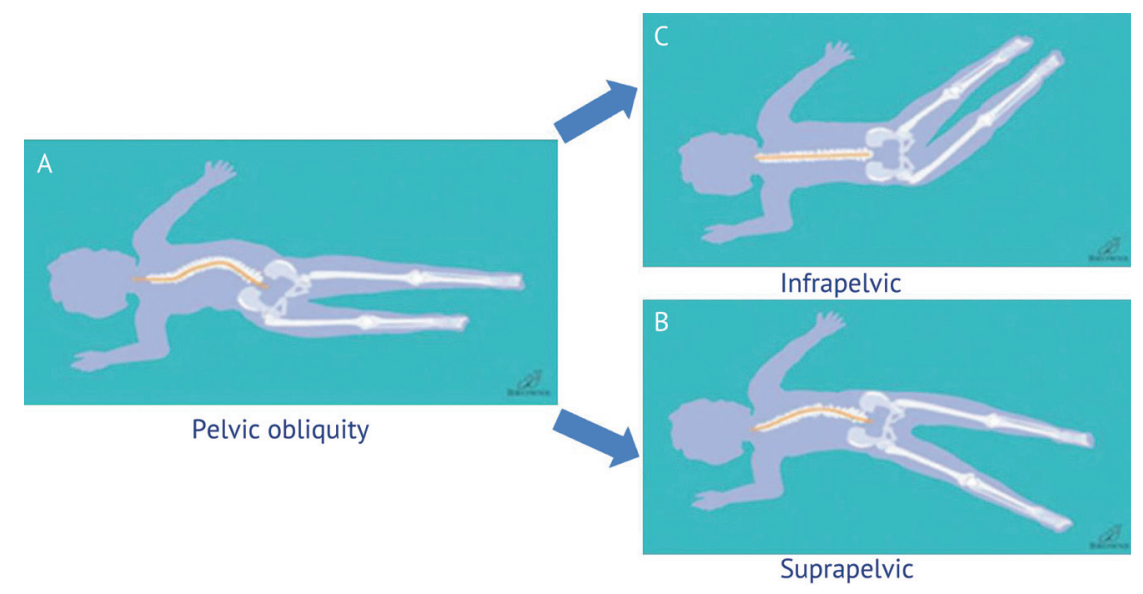

Fig. 2 Types of pelvic obliquity. From «Cerebral Palsy. Authors: Freeman Miller, ISBN 978-0387-27124-8, Springer, 2005» [1] 
Postural control methods including seat supports and functional wheelchairs can be used for control of a spinal deformity [17]. But it should be borne in mind that the increase in functional capabilities is limited due to the inability to control the progression of spinal deformity.

Surgical treatment is considered when non-surgical methods of treatment have no chance of success or poor prognosis. Observation and non-surgical treatment of the curvature are practical for curves measuring Cobb angle less than $40^{\circ}$, for mobile deformities, as well as patients who can maintain a sitting position $[17,18]$. Traditionally, bracing has limitations in reducing the rate of curve progression in CP patients [19,20].

The goals of surgical treatment is aimed at restoring the trunk balance with the possibility of verticalization, stabilizing respiratory disorders and improving the quality of life of patients and associates. The main indications for surgical correction can be identified by an inter-expert consensus $[19,20,21,22,23,24,25,26]$ to include scoliosis $>40^{\circ}$; hyperkyphosis or hyperlordosis $>20^{\circ}$ of the border of the normal sagittal profile, regardless of age, the presence of pronounced chest torsion with thoracic insufficiency syndrome, disturbed global balance of the trunk in the frontal and (or) sagittal plane; rapid progression of deformaty (more than $5^{\circ}$ per year); achievement of verticalization of the patient. Surgical treatment can help patients to balanced sitting and independent use of the upper limbs. Other positive effects include effective respiration and pulmonary clearance, especially in children under 7 years of age, in particular, based on data on the possibility of lung tissue regeneration [27], and promoting proper nutrition. Lordoscoliosis and kyphoscoliosis are more common in patients with GMFCS level V [28]. Correction of hyperlordosis can also be helpful in the treatment of gastroesophageal reflux or upper mesenteric artery syndrome. Finally, spinal surgery significantly simplifies patient care and improves the quality of life of patients and their parents $[29,30]$. Limitations to the operation include grades II and III protein-energy deficiency (BMI $<12$ ); osteopenia (Z-criterion $<-2.5$ ) with rehabilitation to be focused on postural management using technical means of rehabilitation (TMR), pain control and nutritional support.

\section{Surgical correction technique}

Transpedicular multi-support fixation systems can be recommended for more effective correction of deformity in three planes to avoid postoperative external support. Low profile supporting components (monoaxial screws) are used on the convex side of the deformity with atrophic paravertebral muscles in addition to bone allografts for the fusion $[18,30]$. This is important for patients with osteopenia who need more screws as support points and allografts [22].

The recommended fixation zone is from the upper thoracic vertebrae to the pelvis [30, 31, 32]. Current studies report successful restoration of the sagittal and frontal parameters of the spine balance in CP patients, improvement or stabilization of the ambulatory capacity [32, 33, 34]. Insufficient reconstruction of the balance leads to impossible or limited verticalization $[19,33]$.

\section{Surgical planning}

\section{Proximal fixation level}

Two main parameters are used to determine the proximal fixation level in $\mathrm{CP}$ patients including hyperkyphosis of the thoracic spine with a high inclination angle of Th1 (T1 slope) and preservation of head movements. Based on these aspects, the optimal level for Th3 fixation is identified by adequate correction of kyphosis, prevention of proximal transitional kyphosis or insufficient muscle control of the head position in the patients. To prevent the development of the complications, we agree with the specialists who prefer transpedicular fixation for hyperkyphosis of the thoracic spine with Cobb angle $>50^{\circ}$, in particular $[22,33]$.

\section{Pelvic fixation}

The need to realign and fix the pelvis in $\mathrm{CP}$ patients is determined by the functional status of the patient, the ability to walk and the extent of pelvic obliquity. Target fixation of the sacrum and pelvis is to be considered for patients GMFCS levels IV and $\mathrm{V}$ (non-ambulatory patients) and can be technically difficult due to osteopenia. Complications of pelvic fixation include resorption around screws, instability of intrumntation (broken screws or rods, dislocated nuts) and nonunions $[35,36]$.

The biomechanical concept of pivot point (points of rotation) suggests options for rigid screw fixation. A Multi-vector screw placement including fixation at the maximum width (MW-maximum width) with the screw heads being located ventrally from the center of rotation is a more stable version for the screw geometry [37, 38, 39] (Fig. 3A). However, soft tissue deficiency and the complexity of the screws and rod commutation can cause difficulties to be assessed during preoperative planning. The standard option is the use of doublesided or iliosacral screws. We opt to use both in severe osteopenia. The first option is a combination of iliosacral bilateral fixation and transpedicular fixation of S1, the second is os illium fixation + bilateral fixation of the lateral sacral masses (Fig. 3B).

Pelvic fixation significantly improves the balance of the trunk for patients GMFCS levels IV and V at sitting. Fixation of L5 has been shown to result in a recurrence of pelvic obliquity in non-ambulatory $\mathrm{CP}$ patients with and severe pelvic obliquity. On the contrary, mobility at the L5-S1 level is to be maintained in patients GMFCS levels I and II without pelvic obliquity for rotational movements of the trunk during walking [22]. 
Genii Ortopedii, Vol. 27, no 4, 2021

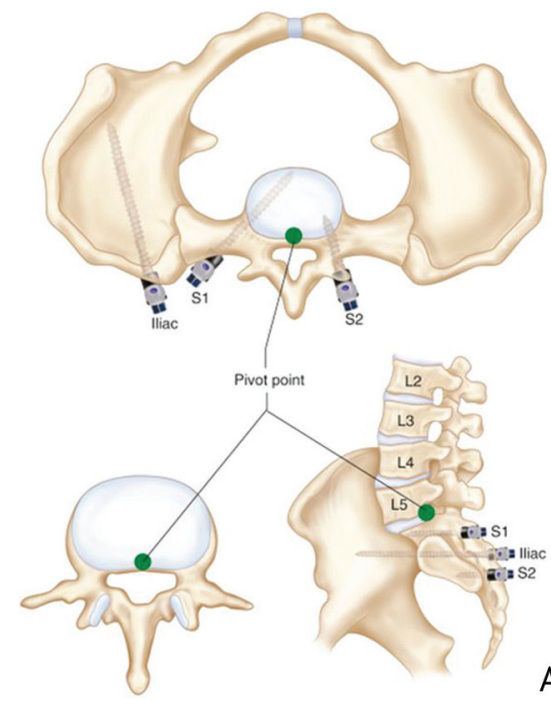

A
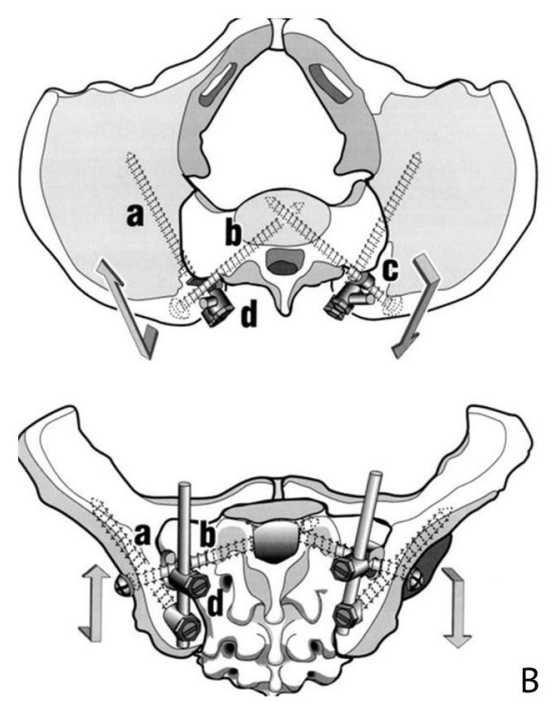

Fig. 3 Options for sacrum and pelvic fixation using screws: (A) according to point of rotation concept described by McCord D.H. et al., 1992 [37]; (B) «MW» geometry according to V. Arlet et al., 1999 [39]

\section{Surgical options}

\section{Dynamic systems}

Assessment of the ambulation status is important for children aged under 7 years with early onset of scoliosis. There is a limited use of TSLO braces in children GMFCS levels IV andV. It is also important to evaluate thoracic insufficiency using the SAL (Space Available of Lung) index. It should be noted that there is an indirect relationship between the ability of lung tissue to grow (in children aged under 7 years) and the volume of the chest [30]. Therefore, it is extremely important to correct spinal deformity to improvement diaphragm position in children aged under 7 years.Dual growing rods are the most commonly used method [40, 41] (Fig. 4). McElroy M.J. et al. reported an improved SAL and a good realignment of pelvic obliquity [41]. We have not found a clear justification of the criteria including age, BMI (body mass index), EDAC (Excessive Dynamic Airway Collapse) has not been found in the literature for identifying the choice of dynamic systems or a multisegmental definitive fixation.

\section{Multilevel fixation}

Transpedicular screws provide three-column fixation allowing for greater correction forces to be applied including rotation to facilitate more effective posterior spinal fusion. Optimal diameter screws should be used for CP patients due to osteoporosis with all segments to be be fixed and allografts used [18, 29]. It is with the installation of At least two pairs of screws placed cranially are recommended to use for fixation with monoaxial screws mounted segmentally on the convex side of the apical arc and at least three pairs of screwsto be fixed caudally (Fig. 5).

\section{Multi-rods Fusion}

Three-rod fixation can be recommended for patients with a curve $>70^{\circ}$ and mobility $<20 \%$. With the spine exposed a segmental facetectomy is performed at the site of instrumentation (Schwab osteotomy 1) and can be added by marginal resection of the arches and ligaments at the level of the apical arch as variations of Ponte Osteotomy, Smith-Petersen Osteotomy (Schwab osteotomy 2). A short apical rod is subsequently placed on the concave side with distraction, then a long rod is placed on the concave side with distraction of the main arc, a long rod is mounted on the convex side of the main arc at the third stage with compression at the level of the main arc (Fig. 6). This option shows better correction results providinga more reliable support along the concave side of the curve. The technique is practical for osteoporotic patients.
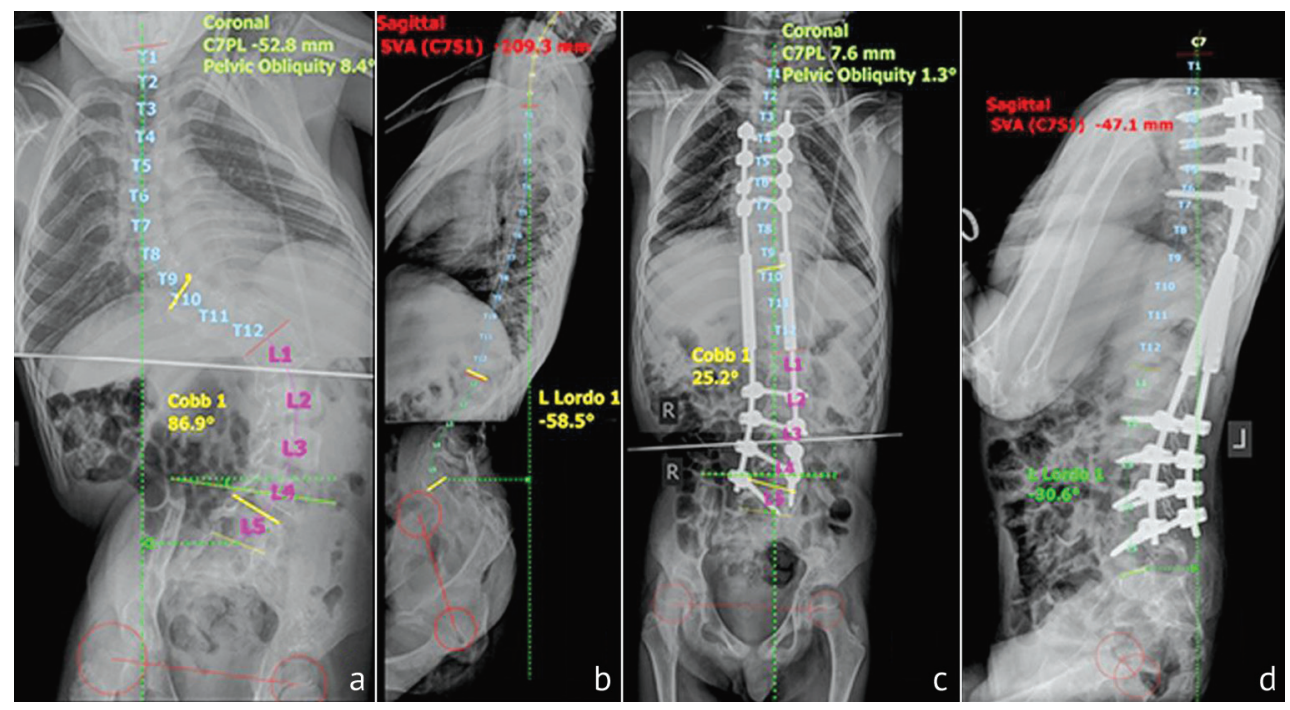

Fig. 4 Radiographs of the trunk of a 10 -year-old patient with neurogenic scoliosis due CP GMFCS level V prior to $(\mathrm{a}, \mathrm{b})$ and following (c, d) dynamic fixation with dual growing rods at the Th4-S1 level (authors ' observation). Preoperative radiographs show a severe main lumbar lordoscoliosis, pelvic tilt and coronal imbalance measuring more than $52 \mathrm{~mm}$. Postoperative radiographs demonstrate a balanced correction 

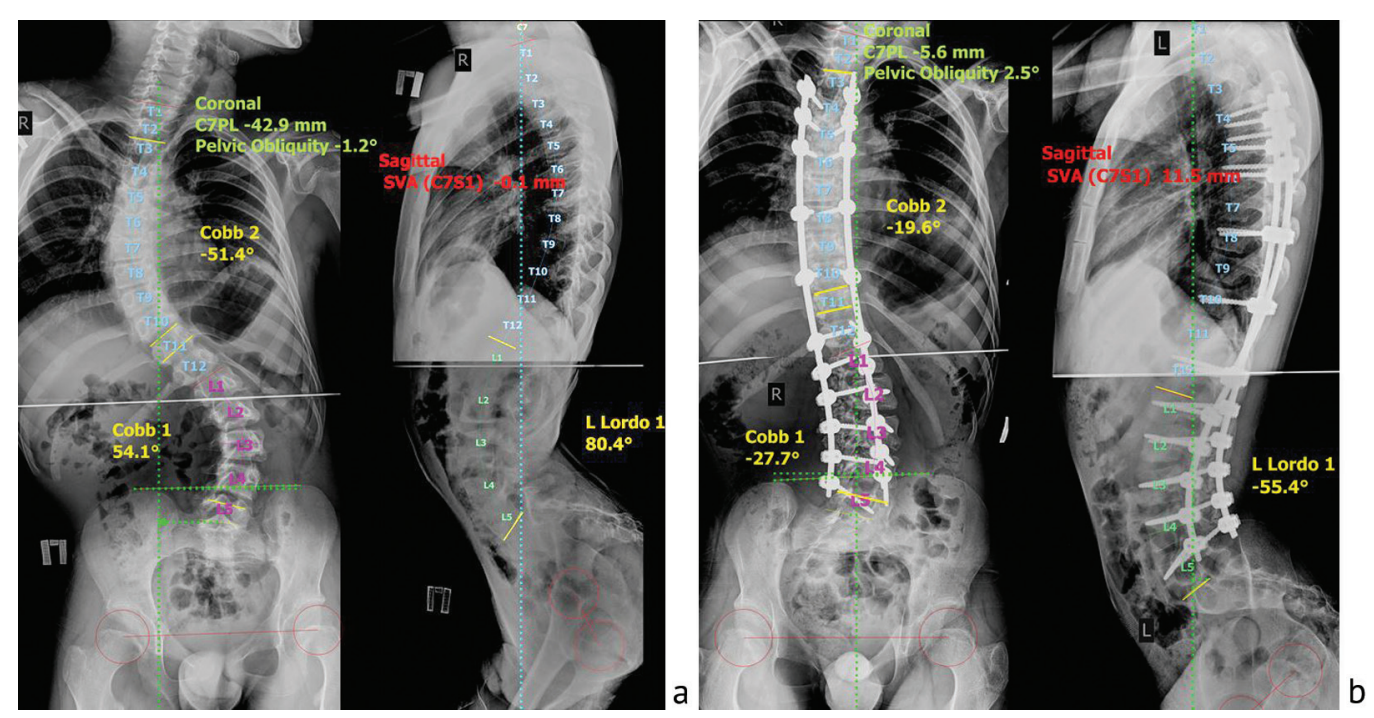

Fig. 5 Radiographs of the trunk of a 14-year-old patient with neurogenic scoliosis due CP GMFCS level IV prior to (a) and following (b) polysegmental fixation at Th4-L5 level (authors' observation).
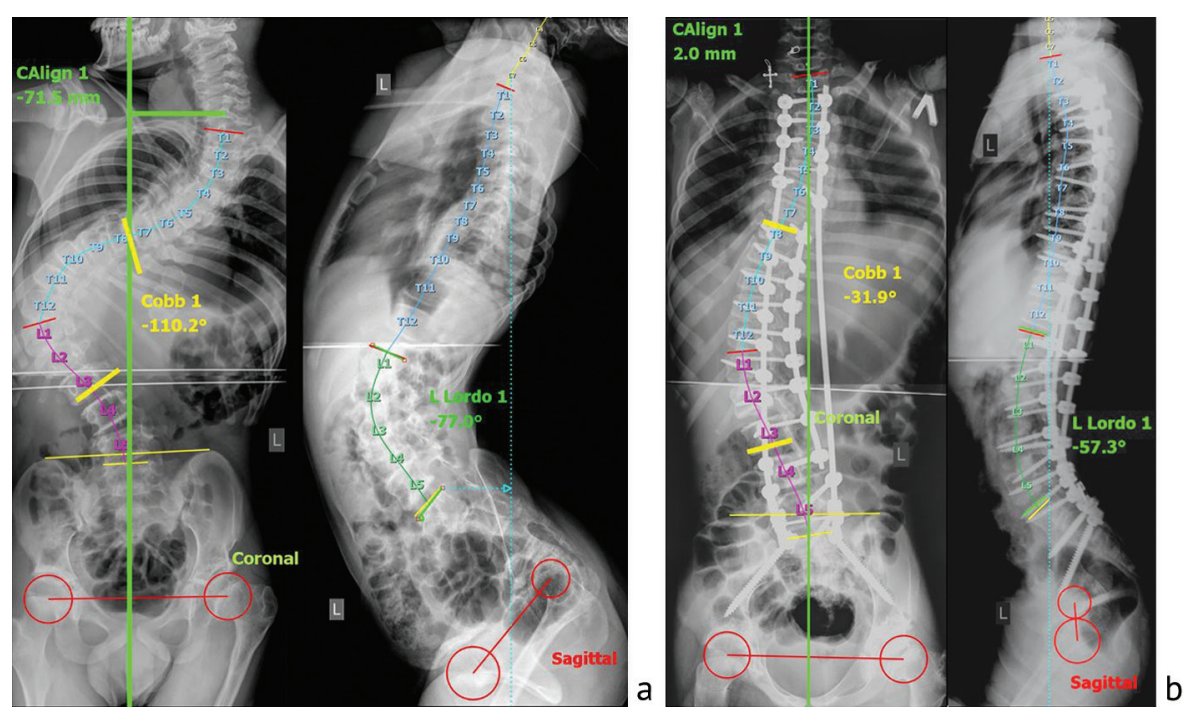

Fig. 6 Radiographs of the trunk of a 14-year-old patient with neurogenic scoliosis due CP GMFCS level $\mathrm{V}$ prior to (a) and following (b) polysegmental three-rod fixation at Th3-os illium level (authors ' observation).

\section{Anterior release}

Anterior mobilization of the spine has no advantages in achieving better spinal fusion for patients with neurogenic scoliosis, and additional risks bring its effectiveness into question. In addition to that, light weight and pathology of internal organs impose additional restrictions [18, 22, 23, 42]. Vialle et al. [43] suggest using a three-rod fixation as an alternative to anterior access. Auerbach et al. [44] concluded that posterior correction and fixation without anterior release in patients with a curvature measuring less than $72^{\circ}$ and mobility up to $40 \%$ showed an excellent correction of the pelvic tilt by $74 \%$, eliminating the risk of complications as compared to the patients who underwent anterior release.

\section{Complications and consequences}

The main risk factors for complications are weight deficiency, insufficient lung volume and chronic infections. Therefore, nutritional support and lung assessment are recommended preoperatively and postoperatively. NIVL would be needed for all CP patients GMFSC levels IV and V with orthopaedic complications who demonstrate hypoatelectases on preoperative CT scans of the lungs [22]. Anterior surgery often exacerbates lung dysfunction and is likely to increase the percentage of postoperative pulmonary complications including pneumonia, pneumothorax, atelectasis and respiratory failure [22]. The risk of neurological disorders associated with surgery is low. Neuromonitoring can be accompanied by a significant number of false negative or positive results and is practically useless. The risk of wound infection after spinal surgery is higher in $\mathrm{CP}$ patients and tends to increase in patients with cognitive impairment and epilepsy when using allografts, as well as in patients with low albumin and lymphocyte count $[42,45,46]$.

Satisfaction of patients or their parents with the results of correction, improvement or stabilization of functional and somatic status is an important concern. Watanabe K. et al. [47] reported the overall satisfaction rate was $92 \%$. Ninety-three percent reported improvement with sitting balance, $94 \%$ with cosmesis, and $71 \%$ in patient's quality of life. Functional improvements seemed limited, but $8 \%$ to $40 \%$ of the patients still perceived the surgical results as improvement. Other authors also reported 
improved quality of life postopertaively. Dias R.C. et al. reported $84 \%$ of patients or parents in a cohort of 31 patients being extremely satisfied with the results of the operation at final follow-up of 2.8 years and would definitely undergo the operation again;
$99 \%$ reported the operation being successful and $79 \%$ recommended the operation to others. The main causes of dissatisfaction reported were wound infection, incomplete correction, hyperlordosis and late postoperative complications [42, 45, 46, 48].

\section{CONCLUSION}

The severity of the manifestations of spinal deformity in CP increases with an increase in the degree of global motor functions and does not depend on the skeletal maturity of the. Spinal deformities cause an imbalance at sitting, bedsores and deterioration of lung and heart functions. Conservative treatment is usually ineffective at a long term, and most patients require surgical correction. Correction and instrumentation transpedicular fixation of the spine allows for three-dimensional correction without the need for anterior spinal fusion. CP patients GMFCS levels IV and $\mathrm{V}$ with pelvic obliquity require pelvic fixation and realigment. Surgical treatment has been shown to significantly improve the body balance, functional level and quality of life.

\section{Limitations}

The unsystematized nature of the data presented and the low level of evidence impose a number of restrictions on the choice of technology recommened, method and treatment options, on the one hand, and determine the need to provide a systematic review, on the other hand.

\section{REFERENCES}

1. Miller F. Cerebral Palsy. New York: Springer-Verlag, 2005. 1055 p. DOI: 10.1007/b138647.

2. Dan B., Mayston M., Paneth N., Rosenbloom L., editors. Cerebral Palsy: Science and Clinical Practice. London, Mac Keith Press, 2014, 648 p.

3. Hasnat M.J., Rice J.E. Intrathecal baclofen for treating spasticity in children with cerebral palsy. Cochrane Database Syst. Rev., 2015 , no. 11. CD004552. DOI: 10.1002/14651858.CD004552.pub2.

4. Modi H.N., Suh S.W., Hong J.Y., Yang J.H. Posterior multilevel vertebral osteotomy for severe and rigid idiopathic and nonidiopathic kyphoscoliosis: a further experience with minimum two-year follow-up. Spine (Phila Pa 1976), 2011, vol. 36, no. 14, pp. 1146-1153. DOI: 10.1097/ BRS.0b013e3181f39d9b.

5. El-Saeed T., Abdel-Azeim F., Ragaee E. Impact of distal static orthotic approach on back geometry in cerebral palsy. Conference: International Society for Prosthetics and Orthotics (ISPO). France, Lyon, 2015. Prosthet. Orthot. Int., 2015, vol. 39, pp. 415. DOI: $10.1177 / 0309364615591101$.

6. Narayanan U., Cahill P., Sponseller P., Abel M., Yaszay B., Parent S., Pahys J., Shah S., Flynn J., Samdani A. Impact of corrective spinal fusion surgery on health related quality of life of children with cerebral palsy. Abstract of 70th Annual Meeting of the American Academy for Cerebral Palsy and Developmental Medicine (AACPDM), September 20-24, 2016, Hollywood, Florida. Dev. Med. Child. Neurol., 2016. Vol. 58, No S5. P. 67-68. DOI: 10.1111/dmcn.98_13224.

7. Pawelek J., Akbarnia B., Hosseini P., Salari P., Marks D., Skaggs D., Emans J., Sponseller P., Thompson G. Traditional growing rod graduates with various diagnoses have similar clinical and radiographic outcomes. Proceedings of the $10^{\text {th }}$ International Congress on Early Onset Scoliosis. New Zealand. 2016. DOI: 10.1016/j.jspd.2016.09.015.

8. Ryabykh S.O., Savin D.M., Medvedeva S.N., Gubina E.B. Opyt lecheniia neirogennykh deformatsii pozvonochnika [The experience in treatment of the spine neurogenic deformities]. Genij Ortopedii, 2013, no. 1, pp. 87-92. (in Russian)

9. Bidiamshin R.R., Netsvetov P.V., Ryabykh T.V., Popkov D.A. Osobennosti ortopedicheskogo i somaticheskogo statusa u patsientov s tiazhelymi formami DTsP, oslozhnennymi vyvikhom bedra [Peculiar features of orthopaedic and somatic condition in patients with severe types of cerebral palsy]. Genij Ortopedii, 2018, vol. 24, no. 1, pp. 33-43.

10. Chibirov G.M., Dolganova T.I., Dolganov D.V., Popkov D.A. Analiz prichin patologicheskikh patternov kinematicheskogo lokomotornogo profilia po dannym kompiuternogo analiza pokhodki $u$ detei so spasticheskimi formami DTsP [Analysis of the causes of pathological patterns of the kinematic locomotor profile based on the findings of computer gait analysis in children with spastic CP types].Genij Ortopedii, 2019, vol. 25, no. 4, pp. 493-500. DOI: 10.18019/1028-4427-2019-25-4-493-500.

11. Lonstein J.E., Akbarnia A. Operative treatment of spinal deformities in patients with cerebral palsy or mental retardation. An analysis of one hundred and seven cases. J. Bone Joint Surg. Am., 1983, vol. 65, no. 1, pp. 43-55.

12. Kim J.H., Kim J.H., Jang S.Y., Kong M.H. Combined chronic occipito-atlantal and atlanto-axial rotator fixation with cerebral palsy. Korean J. Spine, 2013, vol. 10, no. 3, pp. 192-194. DOI: 10.14245/kjs.2013.10.3.192.

13. Leopando M.T., Moussavi Z., Holbrow J., Chernick V., Pasterkamp H., Rempel G. Effect of a Soft Boston Orthosis on pulmonary mechanics in severe cerebral palsy. Pediatr. Pulmonol., 1999, vol. 28, no. 1, pp. 53-58. DOI: 10.1002/(sici)1099-0496(199907)28:1<53::aid-ppul9>3.0.co;2-2.

14. Terjesen T., Lange J.E., Steen H. Treatment of scoliosis with spinal bracing in quadriplegic cerebral palsy. Dev. Med. Child. Neurol., 2000, vol. 42, no. 7, pp. 448-454. DOI: $10.1017 / \mathrm{s} 0012162200000840$.

15. Miller A., Temple T., Miller F. Impact of orthoses on the rate of scoliosis progression in children with cerebral palsy. J. Pediatr. Orthop., 1996, vol. 16, no. 3, pp. 332-335. DOI: 10.1097/00004694-199605000-00007.

16. Nuzzo R.M., Walsh S., Boucherit T., Massood S. Counterparalysis for treatment of paralytic scoliosis with botulinum toxin type A. Am. J. Orthop. (Belle Mead NJ), 1997, vol. 26, no. 3, pp. 201-207.

17. Holmes K.J., Michael S.M., Thorpe S.L., Solomonidis S.E. Management of scoliosis with special seating for the non-ambulant spastic cerebral palsy population - a biomechanical study. Clin. Biomech. (Bristol, Avon), 2003, vol. 18, no. 6, pp. 480-487. DOI: 10.1016/s0268-0033(03)00075-5.

18. Yazici M., Senaran H. Beyin felci ve omurilik deformiteleri [Cerebral palsy and spinal deformities]. Acta Orthop. Traumatol. Turc., 2009, vol. 43, no. 2, pp. 149-155. (in Turkish). DOI: 10.3944/AOTT.2009.149.

19. McCarthy J.J., D'Andrea L.P., Betz R.R., Clements D.H. Scoliosis in the child with cerebral palsy. J. Am. Acad. Orthop. Surg., 2006, vol. 14, no. 6, pp. 367-375. DOI: 10.5435/00124635-200606000-00006.

20. Olafsson Y., Saraste H., Al-Dabbagh Z. Brace treatment in neuromuscular spine deformity. J. Pediatr. Orthop., 1999, vol. 19, no. 3, pp. 376-379.

21. Beckmann K., Lange T., Gosheger G., Bövingloh A.S., Borowski M., Bullmann V., Liljenqvist U., Schulte T.L. Surgical correction of scoliosis in patients with severe cerebral palsy. Eur. Spine J., 2016, vol. 25, no. 2, pp. 506-516. DOI: 10.1007/s00586-015-4107-7.

22. Jones-Quaidoo S.M., Yang S., Arlet V. Surgical management of spinal deformities in cerebral palsy. A review. J. Neurosurg. Spine, 2010, vol. 13, no. 6, pp. 672-685. DOI: 10.3171/2010.5.SPINE09669.

23. Tsirikos A.I. Development and treatment of spinal deformity in patients with cerebral palsy. Indian J. Orthop., 2010, vol. 44, no. 2, pp. 148-158. DOI: $10.4103 / 0019-5413.62052$.

24. Lipton G.E., Miller F., Dabney K.W., Altiok H., Bachrach S.J. Factors predicting postoperative complications following spinal fusions in children 
with cerebral palsy. J. Spinal Disord., 1999, vol. 12, no. 3, pp. 197-205.

25. Hasler C.C. Operative treatment for spinal deformities in cerebral palsy. J. Child. Orthop., 2013, vol. 7, no. 5, pp. 419-423. DOI: 10.1007/s11832013-0517-4.

26. Saito N., Ebara S., Ohotsuka K., Kumeta H., Takaoka K. Natural history of scoliosis in spastic cerebral palsy. Lancet, 1998, vol. 351, no. 9117, pp. 1687-1692. DOI: 10.1016/S0140-6736(98)01302-6.

27. Campbell R.M. Jr., Smith M.D. Thoracic insufficiency syndrome and exotic scoliosis. J. Bone Joint Surg. Am., 2007, vol. 89, no. Suppl. 1, pp. 108122. DOI: $10.2106 / J B J S . F .00270$.

28. Persson-Bunke M., Hägglund G., Lauge-Pedersen H., Wagner P., Westbom L. Scoliosis in a total population of children with cerebral palsy. Spine (Phila Pa 1976), 2012, vol. 37, no. 12, pp. E708-E713. DOI: 10.1097/BRS.0b013e318246a962.

29. Huang M.J., Lenke L.G. Scoliosis and severe pelvic obliquity in a patient with cerebral palsy: surgical treatment utilizing halo-femoral traction. Spine, 2001, vol. 26, no. 19, pp. 2168-2170. DOI: 10.1097/00007632-200110010-00026.

30. Yazici M., Asher M.A., Hardacker J.W. The safety and efficacy of Isola-Galveston instrumentation and arthrodesis in the treatment of neuromuscular spinal deformities. J. Bone Joint Surg. Am., 2000, vol. 82, no. 4, pp. 524-543. DOI: 10.2106/00004623-200004000-00008.

31. McCarthy R.E. Management of neuromuscular scoliosis. Orthop. Clin. North Am., 1999, vol. 30, no. 3, pp. 435-449, viii. DOI: 10.1016/s00305898(05)70096-1.

32. Dabney K.W., Miller F., Lipton G.E., Letonoff E.J., McCarthy H.C. Correction of sagittal plane spinal deformities with unit rod instrumentation in children with cerebral palsy. J. Bone Joint Surg. Am., 2004, vol. 86-A, no. Suppl. 1 (Pt. 2), pp. 156-168. DOI: 10.2106/00004623-200409001-00006.

33. Sink E.L., Newton P.O., Mubarak S.J., Wenger D.R. Maintenance of sagittal plane alignment after surgical correction of spinal deformity in patients with cerebral palsy. Spine (Phila Pa 1976), 2003, vol. 28, no. 13, pp. 1396-1403. DOI: 10.1097/01.BRS.0000067088.99346.73.

34. Tsirikos A.I., Chang W.N., Shah S.A., Dabney K.W., Miller F. Preserving ambulatory potential in pediatric patients with cerebral palsy who undergo spinal fusion using unit rod instrumentation. Spine (Phila Pa 1976), 2003, vol. 28, no. 5, pp. 480-483. DOI: 10.1097/01.BRS.0000048649.72919.6B.

35. Jones-Quaidoo S.M., Arlet V. Review article: Long posterior fixation of the spine 2009 to the sacrum and pelvis. Curr. Orthopaedic Practice, 2009, vol. 20, no. 3, pp. 252-268.

36. Tsuchiya K., Bridwell K.H., Kuklo T.R., Lenke L.G., Baldus C. Minimum 5-year analysis of L5-S1 fusion using sacropelvic fixation (bilateral S1 and iliac screws) for spinal deformity. Spine (Phila Pa 1976), 2006, vol. 31, no. 3, pp. 303-308. DOI: 10.1097/01.brs.0000197193.81296.f1.

37. McCord D.H., Cunningham B.W., Shono Y., Myers J.J., McAfee P.C. Biomechanical analysis of lumbosacral fixation. Spine (Phila Pa 1976), 1992, vol. 17, no. 8 Suppl., pp. S235-S243. DOI: 10.1097/00007632-199208001-00004.

38. O'Brien J.R., Matteini L., Yu W.D., Kebaish K.M. Feasibility of minimally invasive sacropelvic fixation: percutaneous S2 alar iliac fixation. Spine (Phila Pa 1976), 2010, vol. 35, no. 4, pp. 460-464. DOI: 10.1097/BRS.0b013e3181b95dca.

39. Arlet V., Marchesi D., Papin P., Aebi M. The 'MW' sacropelvic construct: an enhanced fixation of the lumbosacral junction in neuromuscular pelvic obliquity. Eur. Spine J., 1999, vol. 8, no. 3, pp. 229-231. DOI: 10.1007/s005860050163.

40. Sponseller P.D., Yang J.S., Thompson G.H., McCarthy R.E., Emans J.B., Skaggs D.L., Asher M.A., Yazici M., Poe-Kochert C., Kostial P., Akbarnia B.A. Pelvic fixation of growing rods: comparison of constructs. Spine (Phila Pa 1976), 2009, vol. 34, no. 16, pp. 1706-1710. DOI: 10.1097/ BRS.0b013e3181ab240e.

41. McElroy M.J., Sponseller P.D., Dattilo J.R., Thompson G.H., Akbarnia B.A., Shah S.A., Snyder B.D.; Growing Spine Study Group. Growing rods for the treatment of scoliosis in children with cerebral palsy: a critical assessment. Spine (Phila Pa 1976), 2012, vol. 37, no. 24, pp. E1504-E1510. DOI: 10.1097/BRS.0b013e31826fabd3.

42. Sponseller P.D., LaPorte D.M., Hungerford M.W., Eck K., Bridwell K.H., Lenke L.G. Deep wound infections after neuromuscular scoliosis surgery: a multicenter study of risk factors and treatment outcomes. Spine (Phila Pa 1976), 2000, vol. 25, no. 19, pp. 2461-2466. DOI: 10.1097/00007632200010010-00007.

43. Vialle R., Delecourt C., Morin C. Surgical treatment of scoliosis with pelvic obliquity in cerebral palsy: the influence of intraoperative traction. Spine (Phila Pa 1976), 2006, vol. 31, no. 13, pp. 1461-1466. DOI: 10.1097/01.brs.0000219874.46680.87.

44. Auerbach J.D., Spiegel D.A., Zgonis M.H., Reddy S.C., Drummond D.S., Dormans J.P., Flynn J.M. The correction of pelvic obliquity in patients with cerebral palsy and neuromuscular scoliosis: is there a benefit of anterior release prior to posterior spinal arthrodesis? Spine (Phila Pa 1976), 2009, vol. 34, no. 21, pp. E766-E774. DOI: 10.1097/BRS.0b013e3181b4d558.

45. Comstock C.P., Leach J., Wenger D.R. Scoliosis in total-body-involvement cerebral palsy. Analysis of surgical treatment and patient and caregiver satisfaction. Spine (Phila Pa 1976), 1998, vol. 23, no. 12, pp. 1412-1424. DOI: 10.1097/00007632-199806150-00022.

46. Szöke G., Lipton G., Miller F., Dabney K. Wound infection after spinal fusion in children with cerebral palsy. J. Pediatr. Orthop., 1998, vol. 18, no. 6, pp. 727-733.

47. Watanabe K., Lenke L.G., Daubs M.D., Watanabe K., Bridwell K.H., Stobbs G., Hensley M. Is spine deformity surgery in patients with spastic cerebral palsy truly beneficial?: a patient/parent evaluation. Spine (Phila Pa 1976), 2009, vol. 34, no. 20, pp. 2222-2232. DOI: 10.1097/ BRS.0b013e3181948c8f.

48. Dias R.C., Miller F., Dabney K., Lipton G., Temple T. Surgical Correction of Spinal Deformity Using a Unit Rod in Children with Cerebral Palsy. J. Pediatr. Orthop., 1996, vol. 16, no. 6, pp. 734-740. DOI: 10.1097/00004694-199611000-00007.

Received: 28.04.2021

\section{Information about the authors:}

1. Sergey O. Ryabykh, M.D., Ph.D.,

Ilizarov National Medical Research Centre for Traumatology and Orthopedics, Kurgan, Russian Federation,

ORCID: 0000-0002-8293-0521,Email:rso@mail.ru

2. Alexander V. Gubin, M.D., Ph.D.,

National Medical Research Center of Traumatology and Orthopedics n.a. N.N. Priorov, Moscow, Russian Federation,

ORCID: 0000-0003-3234-8936, Email: alexander@gubin.spb.ru

3. Dmitry M. Savin, M.D., Ph.D.,

Ilizarov National Medical Research Centre for Traumatology and Orthopedics, Kurgan, Russian Federation,

ORCID: 0000-0002-4395-2103, Email: savindm81@mail.ru

4. Egor Yu. Filatov, M.D., Ph.D.,

Ilizarov National Medical Research Centre for Traumatology and Orthopedics, Kurgan, Russian Federation, ORCID: 0000-0002-3390-807X, Email: filatov@ro.ru

5. Polina V. Ochirova, M.D., Ph.D.,

Ilizarov National Medical Research Centre for Traumatology and Orthopedics, Kurgan, Russian Federation, ORCID: 0000-0001- 5172-4429, Email: poleen@yandex.ru

6. Tat'iana V. Ryabykh, M.D.,

Ilizarov National Medical Research Centre for Traumatology and Orthopedics, Kurgan, Russian Federation, ORCID: 0000-0002-9315-3035, Email: rtatav@rambler.ru

7. Olga M. Sergeenko, M.D.,

Ilizarov National Medical Research Centre for Traumatology and Orthopedics, Kurgan, Russian Federation, ORCID: 0000-0003-2905-0215, Email: pavlova.neuro@mail.ru 